\title{
CAMBIASSU

\section{A mulher derivada: estupro, Estado, estigmas e resistências vocalizadas}

The woman in derivation: rape, State, stigmas and vocalized resistance

\section{Flora Daemon}

Professora do curso de Jornalismo da Universidade Federal Rural do Rio de Janeiro (UFRRI) e do Programa de PósGraduação em Cultura e Territorialidades da Universidade Federal Fluminense (PPCULT-UFF). Doutora e Mestre e Comunicação (PPGCOM-UFF). E-mail: floradaemon@yahoo.com.br 


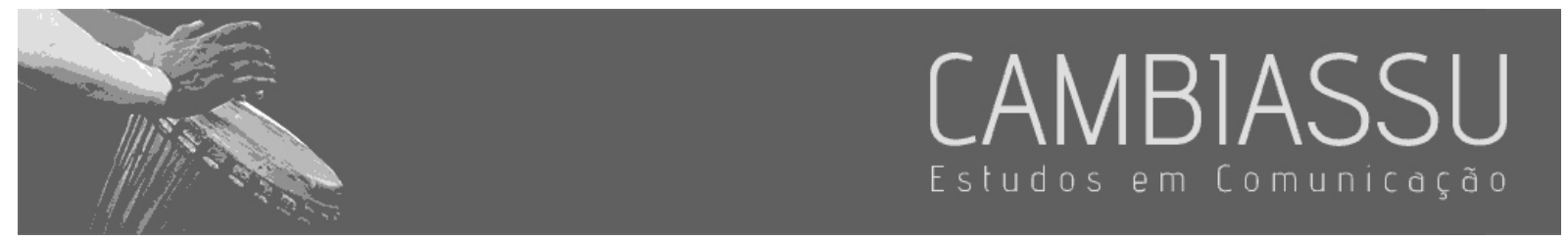

\section{Resumo}

O presente artigo se dedica a observar o momento subsequente à ocorrência de um episódio de violência sexual praticado contra uma mulher. $\mathrm{O}$ estudo busca refletir sobre as categorias acionadas para narrar a pessoa que sofreu violação, bem como suas possibilidades de agência no que se refere à constituição de sua autobiografia após a efetivação do dolo. Para tanto serão apresentadas as seguintes questões norteadoras: É possível pensar a respeito desta mulher sem necessariamente evocar a violência por ela sofrida? Como reconhecer a dimensão do trauma sem reforçar a possibilidade de estigma? Como falá-la? De que maneira conseguimos ouvi-la? Observaremos, desta forma, o Estado - a partir da dimensão jurídica -, o papel das mobilizações feministas na construção dos embates sobre o tema, bem como as práticas de si experimentadas por algumas destas mulheres a partir de suas expressões comunicacionais.

Paldvras-chave: estupro. vítima. Estigma. Autobiografia. mulher.

\section{Abstract}

This article is dedicated to observing the moment after the occurrence of an episode of sexual violence against a woman. The study aims to reflect upon the categories used to narrate the person who was violated, as well as their possibilities of agency with regard to the constitution of their autobiography after the act of intent. Therefore, the following guiding questions will be presented: Is it possible to think about this woman without nec-essarily evoking the violence she suffered? How to recognize the dimension of trauma without reinforcing the possibility of stigma? How to speak of it? How do we listen to it? In this way, we will observe the State - the legal dimension -, the role of feminist mobiliza-tions 
in the construction of conflicts on the subject, as well as the practices of themselves experienced by these women based on their communicational expressions.

Keywords: rape. Victim. stigma. autobiography. woman. 


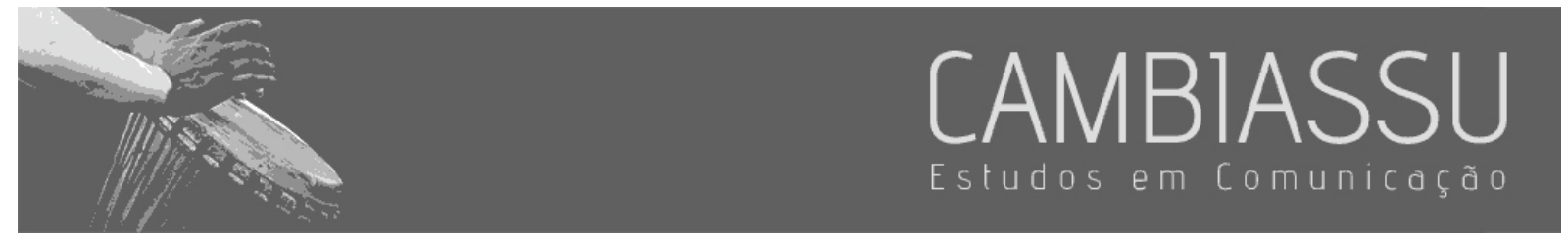

\section{Introdução}

Propomos, na qualidade de questionamentos iniciais, as seguintes questões norteadoras: como narrar o estupro sem converter a mulher, inexorável e cruelmente, em derivado do abuso que a acometeu? Como referenciá-la no período seguinte ao evento traumático? Vítima? Sobrevivente? É possível pensar a seu respeito sem necessariamente evocar a violência por ela sofrida? Como reconhecer a dimensão do trauma sem reforçar a possibilidade de estigma? Como falá-la? De que forma devemos ouvi-la?

Para refletir sobre tais problematizações, nos dedicaremos, inicialmente, a categorias elencadas em campos diversos. Partiremos da dimensão jurídica, representativa da ideia de Estado, para revelar as bases que fornecem sustentação às práticas de violência sexual contra mulheres. Veremos que tanto a letra da lei, quanto as artimanhas discriminatórias são acionadas de forma a atribuir qualificações controversas à vítima e/ou atenuar o ato do perpetrador.

Focalizaremos, também, a atuação das mulheres a partir do princípio de mobilização social. Nos voltaremos a pensar o papel da militância feminista, tanto no intento de denúncia por meio da visibilização de crimes de tal natureza, como as disputas políticas a respeito das possibilidades, riscos e limitações das categorizações de mulheres cujas vidas foram atravessadas por eventos de constrangimento sexual. Em seguida, nos dedicaremos a refletir sobre os espaços possíveis e pertinentes da voz da mulher estuprada em tal arena de disputas políticas. Nosso intuito, nesta etapa da reflexão, é tensionar especificidades do gesto de narrar a partir da condição de sujeito da experiência (do dolo)

\section{Da violência do estupro à problemática dos enquadramentos}

Nos dedicaremos a realizar um retrospecto conciso a respeito do emprego da ideia de honra nos meandros jurídicos, acionada em casos de violência contra a mulher. Nossa proposta é evidenciar 


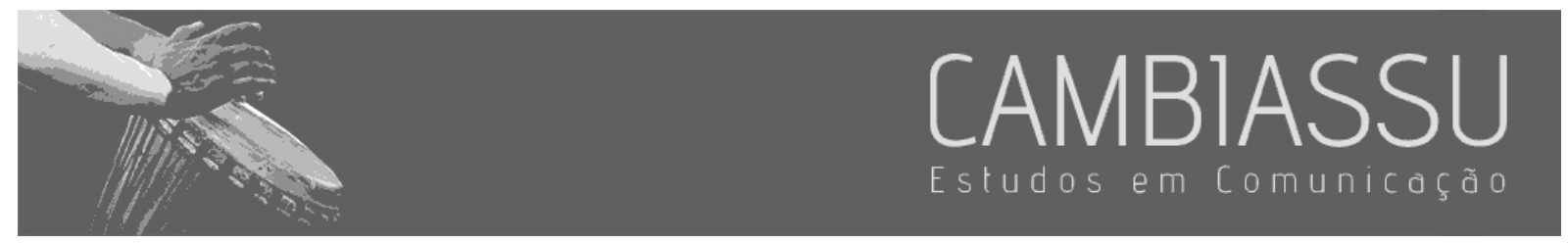

que os avanços viabilizados pelas lutas feministas - garantidos na materialidade da lei -, foram ou permanecem sendo confrontados pelos controversos usos jurisprudenciais que remontam às ideias de impunidade e atenuação de perpetradores, a partir da inclusão, mais ou menos explícita, da dimensão da honra. Tal valoração, como veremos, incidirá diretamente na forma como as categorias serão acionadas para narrar a experiência da violação sexual.

Partimos, assim, das contribuições de Pimentel, Pandjiarjian e Belloque (2001) que, por meio de uma perspectiva sociojurídica de gênero e de direitos humanos, realizaram um estudo crítico a respeito dos chamados crimes contra a honra no Brasil e demais países da América Latina e Caribe. As autoras observaram os dispositivos legais penais discriminatórios acionados em casos de violência sexual, bem como o emprego da figura da legítima defesa da honra. Recorrentemente, tais recursos buscavam atenuar e justificar os dolos ou, ainda, culpabilizar a mulher pela violência exercida contra ela.

A pesquisa encontrou similaridades nos dispositivos legais empregados em diversos países. $\mathrm{Na}$ Argentina, entre os anos de 1998 e 2012, figurou a possibilidade do recurso de avenimiento, um acordo previsto em lei, entre vítima e agressor, que produziria efeitos de extinção do processo penal, se os envolvidos tivessem relação afetiva prévia. Na Bolívia, até os dias de hoje, não há punição do imputado em caso de estupro se o autor do dolo contrair matrimônio com a mulher violada. No Uruguai, até 2005 , era possível realizar o cancelamento da pena se o réu se casasse com a vítima dos crimes de violação, atentado violento ao pudor ou rapto. No Brasil, a referida regra se aplicou até o mesmo ano, quando foram revogados dois incisos do artigo 107 do Código Penal. Nesta oportunidade, alterouse, também, o trecho da lei que estabelecia que o casamento da vítima com terceiro poderia findar a punição ao agressor.

Até 2005, encontrávamos ainda no Código Penal brasileiro evidências explícitas de discriminação contra mulheres por meio da alusão à dimensão do comportamento e da sexualidade. 


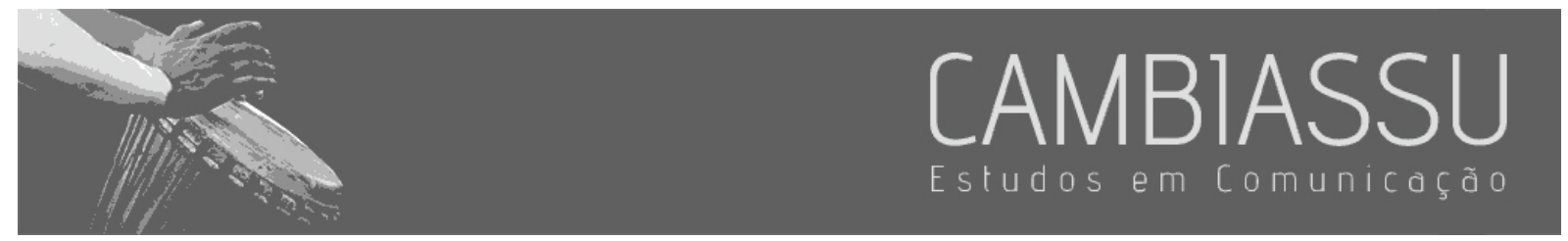

Citamos como ilustração o Artigo $215^{1}$ que tipificava como crime o ato "conjunção carnal com mulher honesta, mediante fraude" [grifo nosso]. O mesmo previa ampliação da pena caso a mulher fosse comprovadamente virgem.

Outro aspecto que merece atenção na legislação brasileira foi a distinção, que vigorou até 2009, entre os crimes de estupro e de atentado violento ao pudor. O primeiro, de acordo com o Código Penal, ocorreria quando da conjunção carnal forçada com penetração vaginal. Já o segundo seria tipificado por ocasião de coito violador de natureza oral ou anal. Tal diferenciação nos parece emblemática na medida em que aludia prioritariamente a dimensão da honra familiar - e a possibilidade de geração de descendente decorrente de gravidez em função do estupro - secundarizando, assim, a dor da pessoa violada. "Se comprova aqui, no discurso legal, a condição da mulher como status-objeto, statusinstrumento de linhagem e de herança, status-dependente e vinculada à honra masculina" (SEGATO, 2010, p. 136) $)^{2}$

Elementos condenatórios da suposta moralidade da vítima são rotineiramente incluídos aos processos. Segato nos lembra que a ausência, na letra da lei, da figura da "legítima defesa da honra" não garante a impossibilidade de sua utilização quando se pretende a caracterização de uma suposta conduta desonrosa. De acordo com a antropóloga, as penas decorrentes de crimes sexuais contra as ditas mulheres honestas são consideravelmente mais severas se comparadas àquelas que tiveram suas condutas associadas à desonra (2010, p. 135).

Ao trazermos para este estudo um olhar sobre as possibilidades de utilização de recursos previstos em lei, nosso intuito é o de apresentar as bases que deram - e ainda dão - sustentação às práticas de violência sexual contra mulheres. Parece-nos revelador e digno de atenção que

\footnotetext{
${ }_{1}^{1}$ Revogações do Código Penal Brasileiro. Disponível em: http://www.planalto.gov.br/ccivil_03/Decreto-Lei/Del2848.htm\#art107vii

2 Tradução nossa. No original: "Se comprueba aquí, en el discurso legal, la condición de la mujer como estatus-objeto, estatusinstrumento del linaje y de la herencia, estatus-dependiente y vinculado a la honra masculina”.
} 


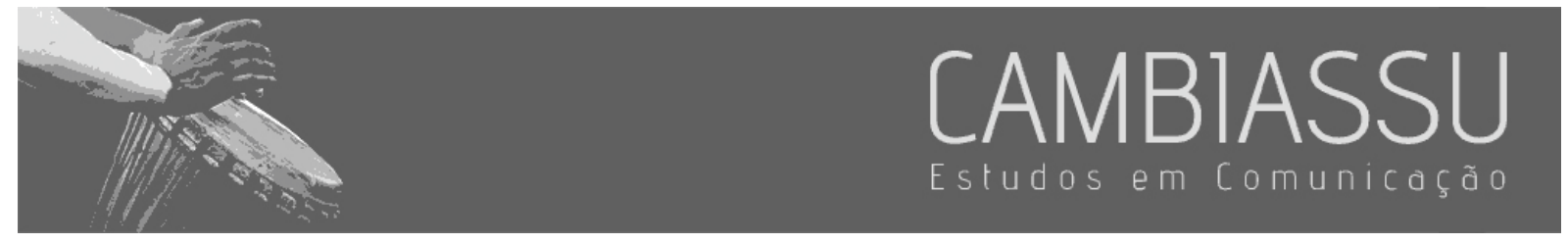

encontremos na letra da lei, muitas vezes, o amparo e o apaziguamento para tais violações, conformados a partir da ideia de reparação moral, de estímulo à impunidade e descredibilização da mulher.

Por mais que retificações necessárias tenham sido realizadas na legislação brasileira, como vimos, sobretudo a partir do ano de 2005, em agosto de 2020 nos deparamos com novo ataque à dignidade de mulheres e meninas violentadas. O Ministério da Saúde publicou uma portaria que dificulta ainda mais o acesso ao aborto legal no país em caso de estupro. Garantido pelo Código Penal desde 1940, a normativa apresentada pelo governo federal orienta que médicos e enfermeiros façam o papel de investigação durante o atendimento às pacientes. Eles deverão registrar e assinar um termo de relato circunstanciado contendo informações como dia, hora e local do fato; tipo e forma de violência; descrição dos agentes da conduta, bem como identificação de testemunhas. Além disso, caberá aos profissionais de saúde preservar "evidências materiais do crime de estupro a serem entregues imediatamente à autoridade policial, tais como fragmentos de embrião ou feto"3. Vale lembrar que tal portaria foi publicada dias depois da ampla publicização do episódio envolvendo uma menina de 10 anos, estuprada e engravidada pelo tio, que teve a interrupção da gestação dificultada por agentes do Estado, incluindo da área de saúde.

Interessa-nos, assim, refletir sobre o papel do Estado na constituição de enquadramentos que instauram categorias, quadros sociais de percepção e interpretação, assim como formas de classificar. Tais operações incidem diretamente na maneira como se organizam as práticas sociais, bem como nas possibilidades de recusa e acatamento de regramentos diversos que se apresentam como naturais. “Onde gênero comparece como polo desestabilizador, o ‘Estado’ parece ser chamado a ocupar - e não

\footnotetext{
3 Portaria N².282, de 27 de agosto de 2020. Disponível em: https://www.in.gov.br/en/web/dou/-/portaria-n-2.282-de-27-de-agosto-de-2020-274644814
} 


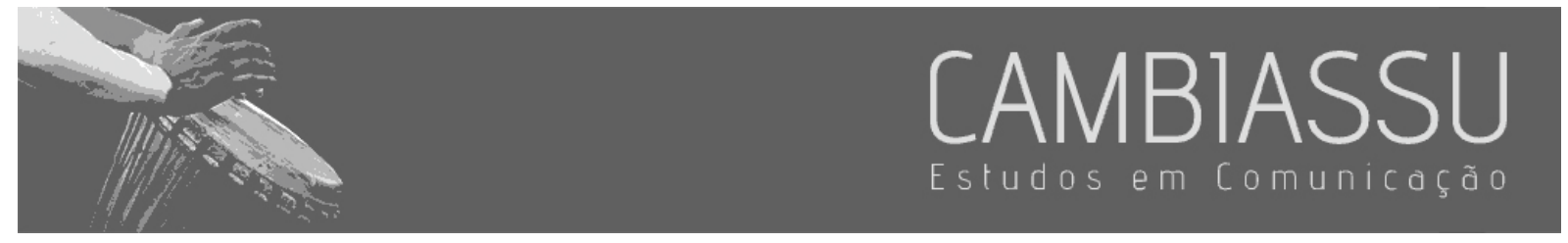

raras vezes ocupa - a materialização dos esforços de estabilização e regramento" (VIANNA; LOWENKRON, 2017: 5).

A questão central deste artigo - as tensões concernentes às categorias acionadas para narrar a mulher violada, bem como suas possibilidades de agência - demandam que pensemos sobre o poder de nomeação que, em termos concretos, se apresenta como o poder do Estado de dar a ver (ou invisibilizar) e de existir (ou de desvanecer). A esse respeito, tomamos, inicialmente, as reflexões de Bourdieu:

Ao enunciar, com autoridade, que um ser, coisa ou pessoa, existe em verdade (veredito) em sua definição social legítima, isto é, é o que está autorizado a ser, o que tem direito a ser, o ser social que ele tem o direito de reivindicar, de professar, de exercer (por oposição ao exercício ilegal), o Estado exerce um verdadeiro poder criador, quase divino (1996, p.114).

O sociólogo complexifica a questão quando reflete sobre a inevitável centralidade do Estado, mesmo quando estamos diante de denúncias que visam o seu questionamento: "uma série de lutas, aparentemente dirigidas contra ele, reconhece, de fato, esse poder ao Ihe pedir que autorize uma categoria de agentes determinados - as mulheres, os homossexuais - a ser oficialmente, isto é, pública e universalmente, o que ela é, até então, apenas para si mesma" (Idem, Ibidem). Podemos entender que a própria noção de categoria, neste sentido, requer que reconheçamos seu caráter impositivo e vertical, sobretudo no que se refere às minorias. Se pensarmos nos termos de Bourdieu, veremos a violência simbólica na qual tal autoridade criadora, entendida aqui enquanto poder de nomeação, se ampara numa lógica em que "[...] o dominado percebe o dominante através de categorias que a relação de dominação produziu e que, assim, estão de acordo com os interesses do dominante" (BOURDIEU, 1996, p. 194).

Situadas noutro campo, encontramos também nas contribuições de Butler (2017) a problematização da ideia de categoria. A percepção da filósofa parte da perspectiva pós-estruturalista para observar os sistemas jurídicos de poder que produzem sujeitos e que, no gesto subsequente, 


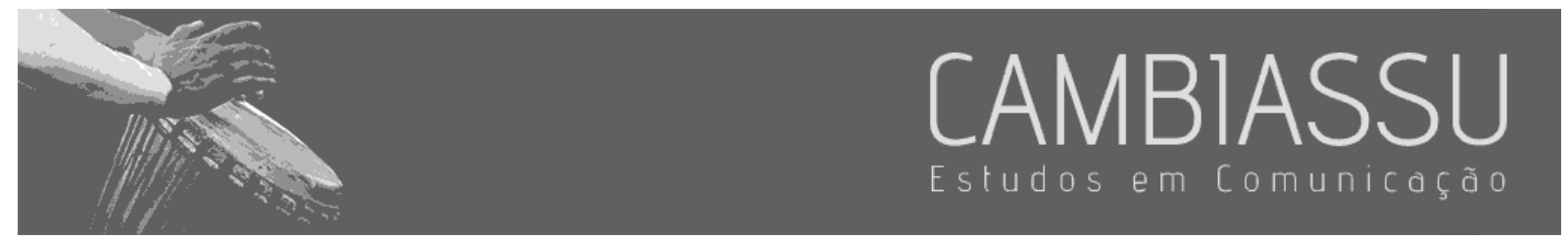

passa a representá-los. De modo provocativo, Butler questiona a crítica feminista que, em sua visão, deveria refletir sobre como a própria '[...] categoria das 'mulheres', o sujeito do feminismo, é produzida e reprimida pelas mesmas estruturas de poder por intermédio das quais se busca uma emancipação" (2017, p.20). Se direcionarmos nosso olhar para o enfoque específico na dimensão da violência nos deparamos, também, com outro questionamento:

Existiriam traços comuns entre as 'mulheres', preexistentes à sua opressão, ou estariam as 'mulheres' ligadas em virtude somente de sua opressão? Há uma especificidade das culturas das mulheres, independente de sua subordinação pelas culturas masculinistas hegemônicas? (BUTLER, 2017, p. 22)

Há como vimos, um dilema concreto na questão dos marcadores distintivos que irão designar categorias e nomeações. Se, por um lado, é possível vislumbrar que a “[...] diferença não é sempre um marcador de hierarquia e opressão. Portanto, é uma questão contextualmente contingente saber se a diferença resulta em desigualdade, exploração e opressão ou em igualitarismo, diversidade e formas democráticas de agência política" (BRAH, 2006, p. 374); é preciso considerar que a impossibilidade de anulação de algumas dessas diferenças é reveladora quando nos voltamos, em específico, às chamadas minorias étnicas e sociais. Ou, nas palavras de Anzaldúa: " $A$ veces yo soy nada ni nadie. Pero hasta quando no lo soy, lo soy."4 (2009, p. 316).

Essa imposição do ser interpelado pelo o que não se é e, assim, tornar-se algo definido e posicionado pelo olhar alheio foi extensamente estudada por pensadores de campos diversos, com destaque para Simone de Beauvoir. Uma das características desse outro é justamente a introjeção de sua sujeição que impossibilitaria a realização de um projeto de transcendência.

Mesmo sob o risco de remontar as críticas sobre as abordagens pós-modernas apontadas como meros exercícios elitistas que separam a teoria da prática, como recorda McLaren (2016) e, com

\footnotetext{
${ }^{4}$ Neste caso, em específico e excepcionalmente, optamos por manter o texto no original e sem tradução. Trata-se de um gesto de respeito à Gloria Anzaldúa que, em suas obras, desenvolveu a ideia de consciência mestiça e os discursos fronteiriços.
} 


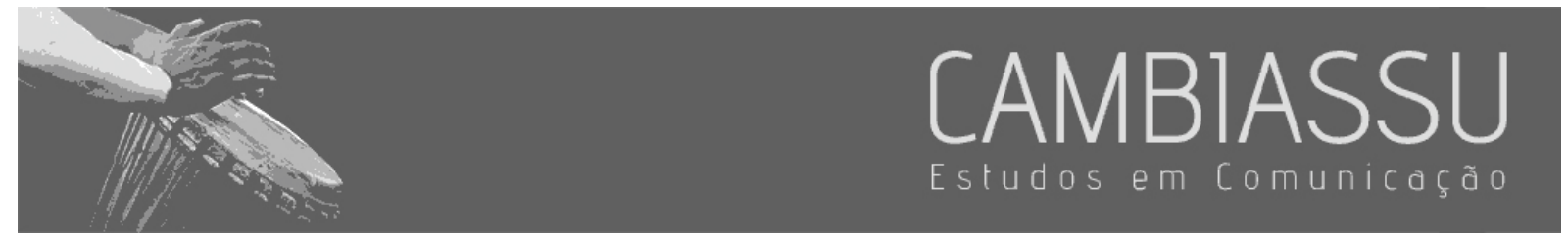

isso, limitar a atenção aos questionamentos convergentes, optamos por trazer para o estudo reflexões que, embora oriundas de campos diversos, focalizam a problemática da constituição das categorias. São elas, como vimos, que atribuem nomeações, sentidos e estigmas por meio de quadros sociais de percepção e interpretação. E é a partir delas que se instaura o "novo status" atribuído forçadamente à mulher cuja trajetória foi atravessada pela violência sexual.

Podemos encontrar na proposição da Teoria do Ponto de Vista Feminista, de Nancy Hartsock (1983), uma outra chave interpretativa para o dilema posto e observado por pensadores diversos. $\mathrm{Na}$ qualidade de autora situada no campo do feminismo marxista, a estadunidense propõe que pensemos a vida das mulheres tomando em perspectiva a vida dos proletários. A cientista política, desta forma, se dedicou a desenvolver uma reflexão de natureza teórico/prática a partir da noção de que o entendimento de sua condição de oprimida, bem como do sistema de exploração falocrático, possibilitaria um privilégio epistêmico às mulheres - tal como ao proletariado - na luta contra sua sujeição.

O desenvolvimento desta linha de reflexão parte de uma tendência resultante da crítica feita por autoras vinculadas aos estudos de gênero à ideia de vitimização. Resultado de um esforço políticoteórico, o pressuposto de tais (re)formulações se baseava na negação da suposta passividade das mulheres diante da dominação masculina observando, sobretudo, as relações intersubjetivas e as ambiguidades inerentes a elas (SARTI, 2011).

Uma das evidências da confrontação da ideia de passividade se situa precisamente na capacidade de articulação em termos de assunção de uma identidade minoritária. De acordo com Sodré (2005), é necessário que deixemos de enxergar minoria como uma fusão gregária mobilizadora para passarmos a compreendê-la como lugar de transformação e passagem. Ele parte, assim, de uma referência topológica - em detrimento da topográfica - para pensar as forças e os fluxos que polarizam diferenças e orientam identificações. Neste sentido, lugar minoritário passa a ser entendido como "[...] 


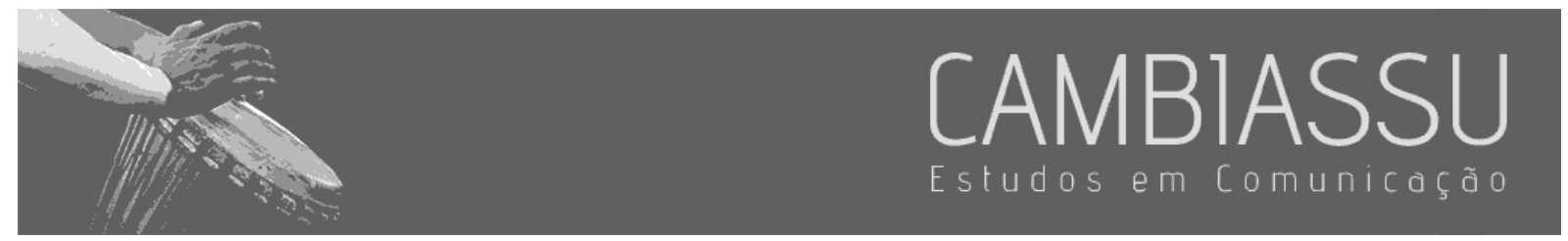

um topo polarizador de turbulências, conflitos, fermentação social. O conceito de minoria é o de um lugar onde se animam os fluxos de transformação de uma identidade ou de uma relação de poder. Implica uma tomada de posição grupal no interior de uma dinâmica conflitual" (SODRÉ, 2005, p. 1).

O pesquisador identifica, ainda, características fundadoras que, em nossa perspectiva, desobrigam as minorias (aqui, em específico, mulheres e mulheres vítimas de violência sexual) de lidar justamente com um caráter de fixidez rotineiramente acionado para nomeá-las e/ou para travar disputas. Ao pensar em tais dimensões - vulnerabilidade jurídico-social, identidade in statu nascendi, luta contra-hegemônica e estratégias discursivas - Sodré propõe um entendimento de minoria como um dispositivo simbólico com intenções ético-políticas, não como "[...] um sujeito coletivo absolutamente idêntico a si mesmo e numericamente definido, mas como um fluxo de mudança que atravessa um grupo, na direção de uma subjetividade não capitalista. Este é na verdade um 'lugar' de transformação e passagem" (SODRÉ, 2005, p. 1).

As lutas das mulheres, neste sentido, devem ser observadas a partir da compreensão de que não há um princípio hegemonista dentro do feminismo, já que este se organiza por meio de experiências realizadas em corpos sexuados diversamente, conforme nos lembra Gargallo. A filósofa parte do entendimento de que o feminismo é o reconhecimento de uma subjetividade em processo a partir de pactos culturais estabelecidos pelas mulheres $(2014$, p. 60$)$.

Tal chave de leitura nos parece fundamental, já que nos dedicaremos, na próxima etapa do artigo, a refletir sobre debates e disputas diante da concretude da violação. Nossa ideia é, justamente, pensar as figuras postas em cena nos discursos sobre violência sexual, bem como os ofuscamentos e desresponsabilizações a partir das categorias acionadas para narrar trajetórias atravessadas pela experiência do estupro.

\section{A concretude do estupro as instabilidades da categoria vítima}




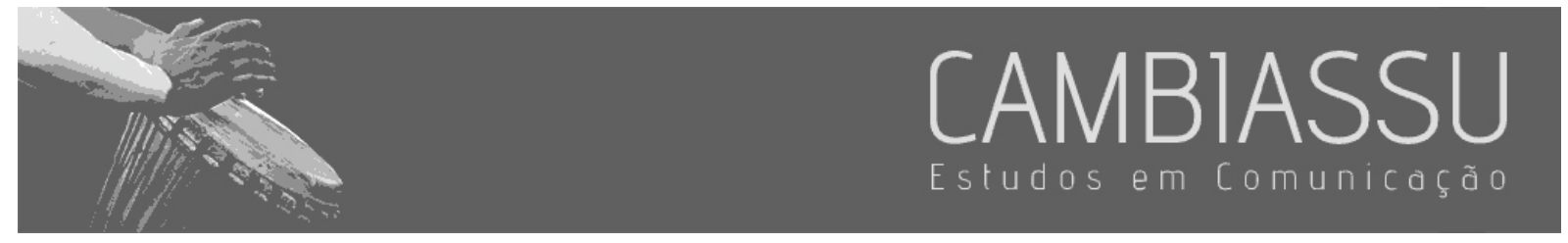

Nesta etapa, nos dedicaremos a pensar sobre a atuação de mulheres mobilizadas a partir da concretude do estupro compreendida - aqui, tanto como uma experiência factual, quanto uma violência em potencial -, na medida em que a violação permeia o universo de meninas e mulheres como um risco inerente à sua própria existência (SEGATO, 2010; 2018). Este entendimento é fundamental para percebermos as formas de engajamento e solidariedade forjadas a partir do reconhecimento do perigo.

Ainda assim, os cuidados e narrativas diante da violência sexual - como risco ou como fato tendem a se apresentar de maneira proporcionalmente discreta, na qualidade de orientações ou silenciamento. Isso ocorre porque ainda permanecem associados às mulheres ideários de pureza e moral que, como vimos na construção dos dispositivos legais penais discriminatórios, podem incidir nas formas de articular os argumentos de culpabilização das vítimas e são reveladoras do caráter machista que encontra eco na sociedade. Nas últimas décadas, porém, o estupro passou a ganhar uma evidência pública em função da luta de mulheres que tentaram trazer para a luz o drama de muitas e o temor de todas.

Considerado emblemático, o juízo referente ao caso das belgas Anne Tonglet e Aracelli Castellano, ocorrido em 1978, na França, ilustra o esforço político empreendido tanto para uma correta tipificação do estupro, quanto para a inclusão da voz das vítimas para remontar a violência sofrida. Em 1974 as duas jovens acampavam próximo à Marselha quando foram violadas por três homens durante quatro horas. A justiça do país, à época, embora considerasse a violação sexual como um crime, tratava as acusações como contravenção, reduzindo-as à agressão e espancamento. A lei francesa entendia que a ocorrência do estupro dependia, ainda, da penetração e subsequente ejaculação.

Pela primeira vez na história do país, vítimas de violação sexual foram ouvidas pelo Cours d'Assises, tribunal penal responsável por crimes de maior gravidade, muito em função da pressão social fomentada pela luta feminista, articulada por diversas mulheres, dentre elas Gisèle Halimi, advogada das vítimas. A estratégia jurídica precisou, inclusive, expor o fato de suas clientes serem lésbicas para 


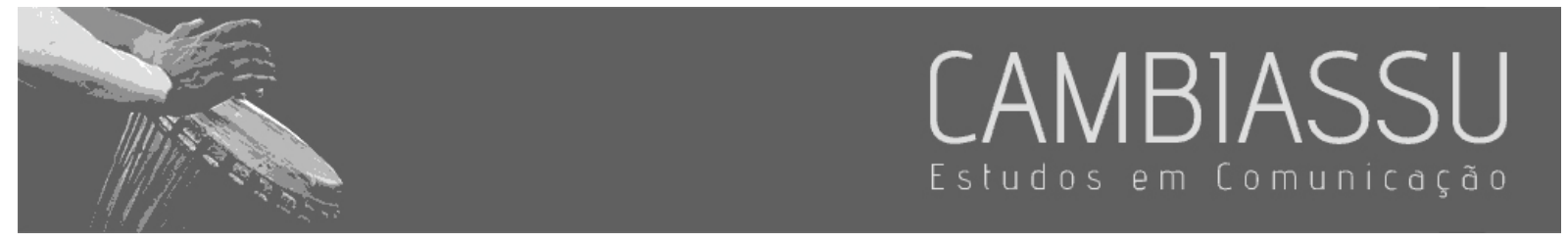

desmontar o argumento central dos advogados dos réus que se baseava na ideia de consentimento implícito das mulheres. Ainda assim, estes alegaram se tratar de uma moral incomum a seus clientes, referenciando, justamente, o comportamento e a orientação sexual para culpabilizar as vítimas.

A defesa também buscou invalidar o processo de julgamento a partir da afirmação de que se tratava de uma interferência das mulheres francesas no âmbito da justiça em função de sua ampla mobilização social. De acordo com um dos advogados, aquele não era "mais o julgamento de duas jovens, mas de todas as mulheres" 5 - o que, em sua perspectiva, revogava a legitimidade da condução do processo penal que sedimentou o terreno para criação da lei que passou a criminalizar corretamente a violação sexual, seis anos após o crime.

Nosso objetivo, ao trazermos pare este estudo o referido caso, é o de destacar dois aspectos concernentes ao debate que realizamos: a importância da mobilização feminista para a conquista de direitos básicos e a inclusão da voz da mulher no âmbito da justiça a partir de parâmetros inéditos. Está em jogo, neste sentido, a própria noção de sofrimento como algo que precisa ser reconhecido para que seja consolidada - de fato, a ideia de vítima. Para refletirmos a este respeito, partimos das contribuições de Mauss (1979), Eliacheff e Larivière (2009), Wieviorka (1997) e Sarti (2011) com o intuito de perceber como tal categoria aparece sujeita à sua própria contestação, não existindo, por princípio, uma estabilidade inerente.

A concepção da categoria vítima está submetida à sua noção histórica definida a partir do estabelecimento da ideia de sujeito, por um lado, e do que poderia ser tipificado como violência, por outro (WIEVIORKA, 1997). O entendimento sobre o que pode ser considerado como uma ação violenta varia de acordo com os graus de rejeição, condenação e tolerância diante de um evento específico (KAPLER, 2010).

5" France jails papists after pivotal case". The New York Times, 4 de maio de 1978. Disponível em: https://www.nytimes.com/1978/05/04/archives/france-jails-rapists-after-pivotal-case-precedent-set-by-criminal.html 


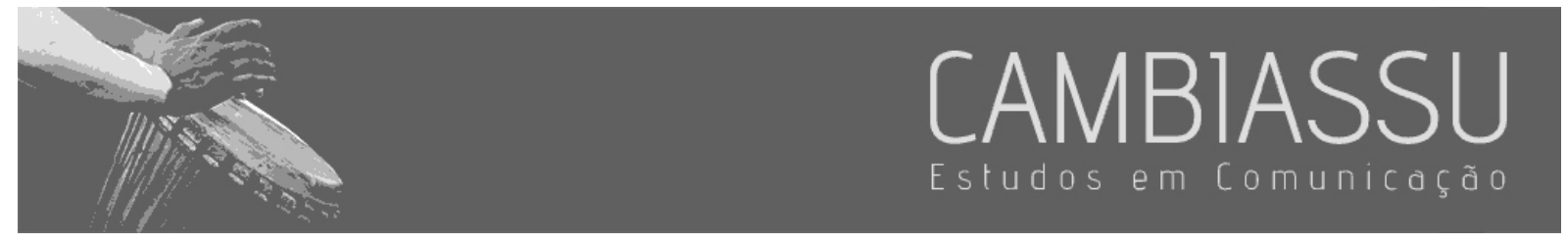

A noção de violência sexual, portanto, não deve ser tomada como universal, podendo tanto promover rechaço, quanto gerar fascinação ${ }^{6}$. Facio (2000) entende que tal instabilidade é fruto da dificuldade de incorporação das mulheres ao campo do que é considerado humano. De acordo com ela, se tal entendimento fosse aceito e partilhado, seria possível pensar que as violências direcionadas às mulheres são, por princípio, uma violação dos direitos humanos.

Outro aspecto que merece destaque se refere ao fato de que mesmo diante do reconhecimento público do caráter abjeto da violação sexual há, nos processos judiciais, nas narrativas jornalísticas e num certo entendimento do senso comum, uma recorrente corresponsabilização da vítima pelo dolo sofrido, como vimos. Neste sentido, a ideia de vitimização seria atenuada na medida em que se apresentam associadas às mulheres hábitos ou traços supostamente questionáveis; enfraquecendo, assim, a agressão e, por decorrência, a posição de vítima.

Identificamos, ainda, outra zona de sensibilidade no que se refere ao caráter instável da categoria. Esta se desenvolveria a partir da interpretação de que para ser vítima o sujeito que sofreu a agressão não poderia transcender a violência sofrida, mantendo-se como derivado da violação e, por isso, inviabilizando a assunção pública do movimento de superação. Este debate implica, como veremos adiante, uma problematização dos desafios postos à pessoa agredida diante de seu intento de reposicionamento social.

Gargallo $(2014$, p. 48) rememora uma discussão acerca dos termos acionados para referir-se a mulheres que sofreram violência de natureza sexual. Conta que, durante um debate, foi questionada sobre o fato de utilizar a expressão vítima para qualificar uma mulher violada. A crítica surgiu juntamente com uma sugestão substitutiva, com vistas ao uso de uma palavra que se apresentava de maneira mais alinhada à perspectiva do empoderamento. Trata-se da categoria sobrevivente que, na visão da antropóloga, não cumpre o papel de designar aquelas cujas trajetórias foram atravessadas pela

\footnotetext{
${ }^{6}$ Sobre tal debate, ver DAEMON (2020).
} 


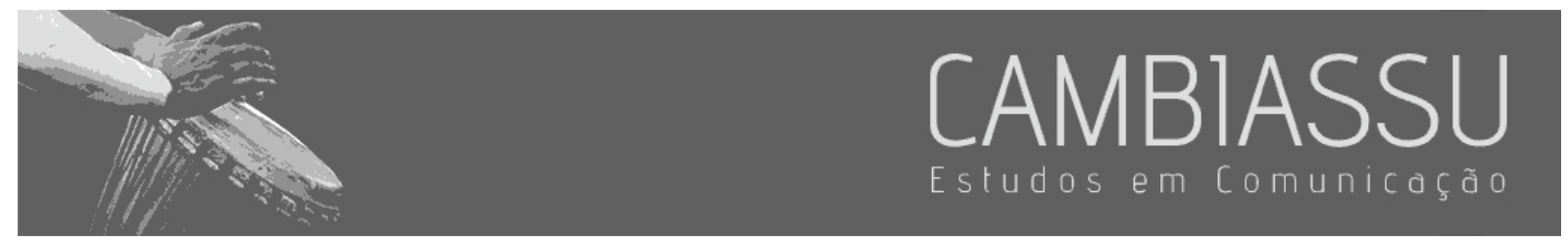

imposição de uma violência injusta. Sobreviver caberia mais apropriadamente em casos de acidentes ou tragédias naturais. Tal abrangência, em sua visão, despolitizaria o dolo e desresponsabilizaria o sujeito da ação aqui, em específico, o estuprador.

Sarti (2011) observa que o lugar social da vítima está diretamente ligado à maneira como o sofrimento ganha reconhecimento e inteligibilidade social. "A forma de manifestação do sofrimento precisa fazer sentido para o outro. Assim, não apenas sentir, mas expressar a dor e o sofrimento supõe códigos culturais que sancionam as formas de manifestação dos sentimentos". (2011, p. 56). Trata-se, em última análise, de uma linguagem. Será sobre ela que nos debruçaremos nas próximas linhas.

\section{Dar-se a ver e a ouvir: a fald da mulher violada}

$\mathrm{Na}$ última etapa da presente reflexão, nos voltaremos a observar formas possíveis de constituição de uma narrativa pública, a partir da assunção da condição concreta de vítima de estupro. Mais do que delinear uma análise detalhada dos casos, interessa-nos, aqui, identificar as referências acionadas em tais relatos, com vistas a perceber os espaços possíveis e pertinentes à voz da mulher estuprada numa arena de disputas políticas sobre a qual discutimos anteriormente.

Para tanto, partimos do entendimento de Mauss (1979, p. 153) de que a manifestação do sofrimento é uma ação de caráter simbólico, direcionada precisamente aos outros e por conta dos outros. Isso denota que o gesto de narrar tal sentimento apresenta uma carga de intencionalidade e um intuito de implicação que estabelece, mesmo que eventualmente a contragosto, uma vinculação com o sujeito da escuta. Tomemos, pois, o relato da escritora Clara Averbuck que tornou público, por meio de uma publicação em uma rede social, o estupro que sofreu dentro de um Uber:

bom, virei estatística de novo. queria chamar de "tentativa de estupro" mas foi estupro mesmo. tava bêbada? tava. foda-se. não vou incorrer no mesmo erro de quando eu era adolescente e me culpar. fui violada de novo, violada porque sou mulher, violada porque estava vulnerável e mesmo que não estivesse poderia ter acontecido também. o nojento do motorista do uber aproveitou meu estado, minha saia, minha calcinha 


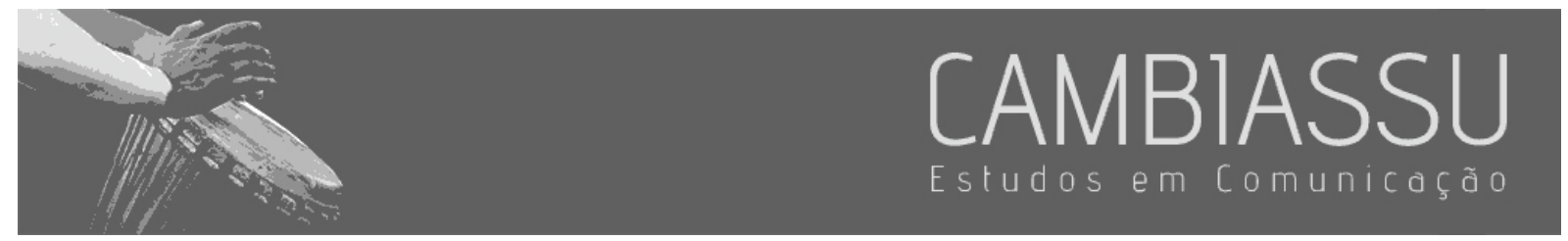

pequena e enfiou um dedo imundo em mim, ainda pagando de que estava ajudando "a bêbada". estou machucada mas estou em casa e medicada pra me acalmar. estou decidindo se quero me submeter à violência que é ir numa delegacia da mulher ser questionada, já que a violência sexual é o único crime que a vítima é que tem que provar. não quero impunidade de criminoso sexual mas também não quero me submeter à violência de estado. justamente por ter levado tantas mulheres na delegacia é que eu sei o que me espera. estou ponderando. estou com o olho roxo e a culpa de ter bebido e me colocado em posição vulnerável não me larga. a culpa não é minha. eu sei. a dor, a raiva e a impotência também não me largam. estou falando tudo isso para que todas as que me lêem saibam que pode acontecer com qualquer uma, a qualquer momento, e que o desamparo e o desespero são inevitáveis. o mundo é um lugar horrível pra ser mulher (AVERBUCK, 2017).

A exposição pública do episódio pela escritora revela a dificuldade de desvinculação da ideia de culpa que, como vimos, é fundadora da dinâmica das práticas institucionais. Apesar de saber-se não responsável pela violência alheia em seu corpo, é possível notar, no depoimento, a referência inevitável à noção de responsabilidade própria pelo dolo sofrido. Como uma fala que se organiza em movimento espiral, Averbuck transita entre culpabilizar o perpetrador, o Estado e as estruturas coniventes e se situar no lugar da vítima circunstancialmente forjada a partir de uma suposta displicência própria. Eis, aí, a armadilha posta ao sujeito da fala a partir da condição concreta de vítima de um estupro. "Essas vítimas ora despertam admiração por terem superado a vergonha, ora desagrado pela arrogância de tê-la tornado uma façanha que nos é de bom gosto em expressar publicamente"7 (ELIACHEFF; LARIVIĖRE, 2009, p. 81)

A culpa exteriorizada por Averbuck é distinta daquela que Emma Sulkowicz buscou exprimir com seu gesto-narração. Durante a graduação na Universidade de Columbia, nos Estados Unidos, a jovem foi estuprada por outro aluno no alojamento estudantil. Após o ocorrido, ela recorreu à instituição de ensino que, de acordo com a própria, não acolheu devidamente sua denúncia, assim como a polícia.

\footnotetext{
7 "Estas víctimas suscitan unas veces admiración por haber superado la vergüenza, otras veces desagrado por la arrogancia de haberlo convertido en una hazaña que nos es de buen gusto expresar públicamente" (ELIACHEFF; LARIVIĖRE, 2009, p. 81)
} 


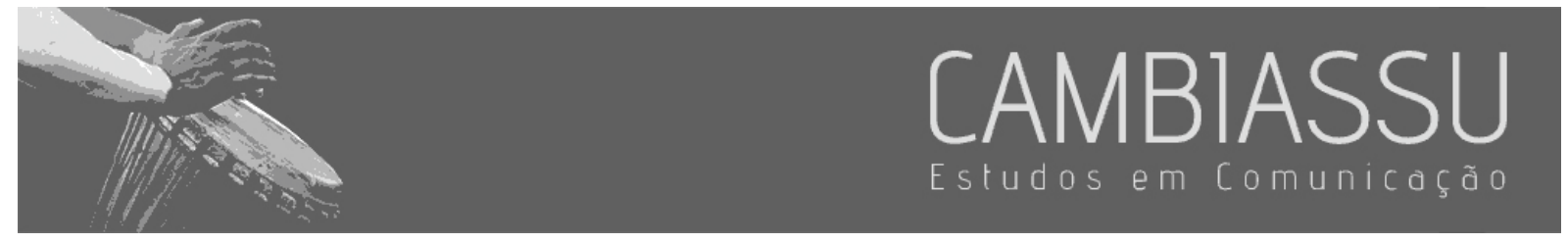

Sulkowicz, então, desenvolveu uma forma de expressar a agressão sexual e a carga emocional inerente à exposição das violências. Ela escolheu o terreno das artes para dar-se a ver a partir da condição de vítima - de estupro e da surdez institucional - e realizou uma obra-protesto, intitulada "Desempenho de colchão (Carregar esse peso)"8. Como um manifesto itinerante, seu trabalho consistia em carregar o colchão no qual ocorreu o estupro durante todo seu percurso dentro do campus. O trajeto da jovem no chão da universidade inscrevia publicamente, a partir do esforço físico e emocional, a dimensão cotidiana da violação que acomete, potencialmente, todas as mulheres. A obra somente teria fim quando da formatura de Sulkowicz ou resolução do caso.

A dor da violência, como experiência traumática, pode, no entanto, ser ressignificada em momentos posteriores de elaboração, o que torna relevante o contexto de sua manifestação e o de sua elaboração, a partir do discurso de quem fala. Essa perspectiva implica discutir as condições de possibilidade de elaboração das experiências de dor e sofrimento, articulando aspectos subjetivos e contexto social e político, de forma a buscar o que permite falar ou o que faz silenciar. (SARTI, 2011, p. 57)

O último caso que traremos para o presente artigo remonta a ideia de redenção. Por meio de uma carta endereçada a si própria, que precisava incluir o olhar do(s) outro(s) para que o remetente encontrasse o destinatário, a nadadora olímpica Joanna Maranhão desenvolve uma narrativa em que as temporalidades merecem destaque:

Oi, Jujuca, tudo bem? (...) Te escrevo para te falar uma coisa que você precisa lembrar para o resto da sua vida: VOCÊ NÃO TEM CULPA. Sei que você pensará isso várias vezes, sei que esse sentimento fará de você sua principal adversária, sei que esse pensamento terá o poder de tirar esse sorriso, mas confia em mim, você é forte o suficiente para superar tudo isso. (...) Vai achar que seu maiô estava muito cavado e que a mão do treinador, que passou por ele quando você nem sequer sabia o que aquilo significava, é fruto de um comportamento seu. Ser mulher é muito difícil e você descobrirá isso quando ainda é uma criança. (...) Os minutos nos vestiários do Náutico serão os piores da sua vida. Sem saber para onde ir, o que fazer e como agir, você resolverá silenciar. Na realidade, isso nem será uma decisão consciente. É uma fuga.

\footnotetext{
8 Tradução nossa. No original: Mattress Performance (Carry That Weight).
} 


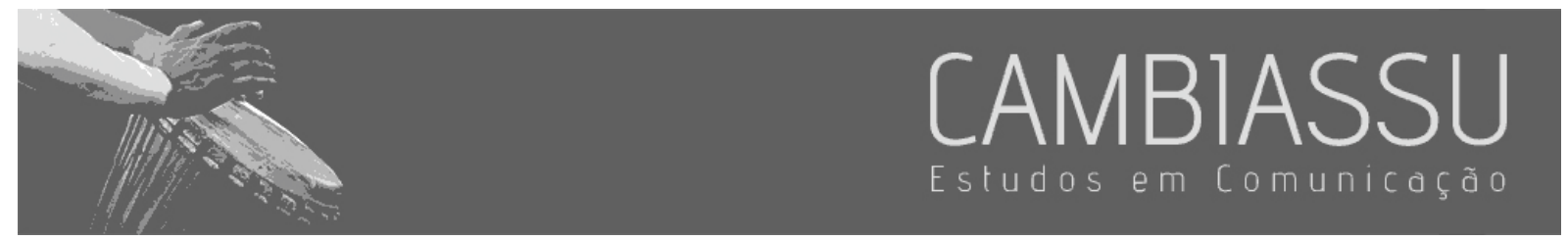

Até dará uma vontade de falar, mas ninguém vai te ouvir. Não culpe as pessoas, isso faz parte da nossa cultura, que dificilmente trata desses assuntos com crianças. Nade. Por alguns anos, esse será o seu refúgio. (...) Você deve estar se perguntando como alguém que está sofrendo tanto pode ter uma carreira vitoriosa. Pois é, é justamente nesse conflito que você notará que precisa superar seu maior adversário: você. (...) Ninguém entenderá que você terá que enfrentar dois processos pesados de depressão. Poucas pessoas saberão que você se entupiu de remédio, quase se matou, para minimizar a dor interna. Você será apenas uma nadadora que perdeu cerca de 15 segundos. Por isso, fale. Fale para você, fale para o mundo. Você tem coragem para isso. (...) Chegou a hora de encerrar esse capítulo. (...) Nunca será fácil, Jujuca. Mas você consegue. A gente consegue ${ }^{9}$.

O gesto de Maranhão de reunir-se com si própria por meio da publicização de um relato íntimo se baseia na ideia de transcendência a partir da inclusão de terceiros. Estes, podemos supor, não são autores do dolo, não estiveram presentes durante o ato da violência em si, não são responsáveis diretos pelo sofrimento da nadadora, mas foram convocados para o momento de reconciliação de uma trajetória íntima fragmentada pela dor.

\section{CONSIDERAÇÕES FINAIS}

Arfuche, em suas reflexões sobre a subjetividade, diante do desejo de constituição de um espaço biográfico a partir do próprio da experiência, recorda-nos: "qual é o 'princípio’ de uma história de uma vida ? Como se 'deve' falar quando se fala sobre si mesmo?"10 (2010, p. 135).

Estaríamos diante da transição da dor para o sofrimento que possibilitaria, justamente, uma expressividade que demanda o olhar alheio. Recorremos, assim, finalmente, à distinção proposta por Birman para entender essa passagem. "[...] A dor é uma experiência marcadamente solipsista, restringindo-se o indivíduo a si mesmo, não revelando este então qualquer dimensão alteritária" (2003,

\footnotetext{
9 Disponível em https://www.geledes.org.br/acabou-jujuca-e-agora-escrevo-para-te-dizer-que-voce-nao-teve-culpa/ . Acessado em 29 de setembro de 2021.

10 Tradução nossa. No original: “¿cuál es el 'principio' de una historia - de una vida -? ¿ Cómo se 'debe' hablar al hablar de sí mismo?"
} 


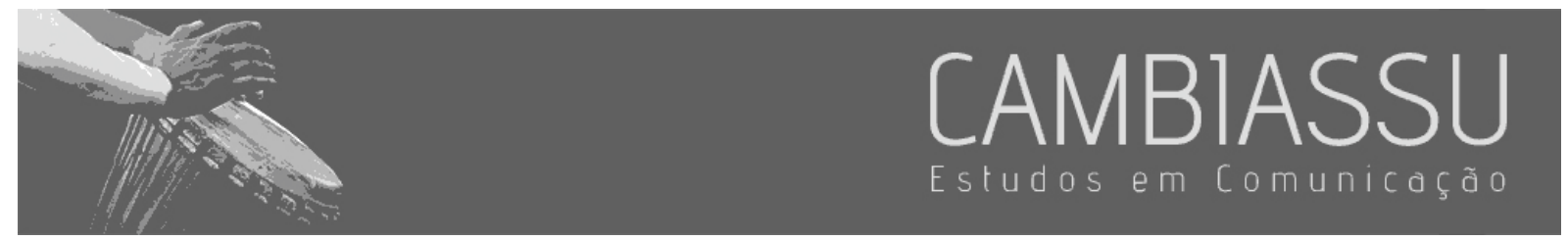

p. 5). O sofrimento, ao contrário, congrega a presença do outro, como uma demanda endereçada, uma atividade de interlocução (idealizada) por meio da qual se coloca a expressão do sofrimento.

Ao longo deste artigo buscamos refletir sobre um desafio que se apresenta de maneira tautológica às mulheres que foram vítimas de violência sexual: narrar ou não a experiência desta dor não é impeditivo do sofrimento próprio ou de terceiros. Há, no gesto de exposição do trauma, uma consciência expressiva que não pede permissão para legitimar-se. A arena de disputas está posta. Trata-se, a nosso ver, de uma ressignificação a partir da substituição da ideia de sujeito da dor, derivado, para a assunção de pessoa em sofrimento, condição passível de mudança. A transcendência, mesmo que discreta, se organiza, também, pelo que há de político no(s) discurso(s).

\section{Referências Bibliográficas}

ANZALDUA, Gloria. Como domar uma língua selvagem. Cadernos de Letras da UFF, no 39, p. 297-309, 2009.

ARFUCH, Leonor. El espacio biográfico. Dilemas de la subjetividade contemporânea. Buenos Aires: Fondo de Cultura Económica, 2010.

BIRMAN, Joel. Dor e sofrimento num mundo sem mediação. Estados Gerais da Psicanálise: II Encontro Mundial, 2003. Disponível em: <http://www.machadodeassis.net/download/rev_artigo01.pdf>. Acesso em: 02 de maio de 2020.

BOURDIEU, Pierre. Razões Práticas: Sobre a teoria da ação. Campinas, Papirus, 1996.

BRAH, Avtar. Diferença, diversidade, diferenciação. Cadernos pagu (26), Janeiro-Junho de 2006.

BUTLER, Judith. Problemas de Gênero: feminismo e subversão da identidade. 13ª Ed. Rio de Janeiro, Civilização Brasileira, 2017b. 2017.

Quadros de Guerra: quando a vida é passível de luto? 3를. Edo de Janeiro, Civilização Brasileira,

DAEMON, Flora. Trace the Rapists: entre as imagens violentas e a violência das imagens. Revista Parágrafo: Janeiro-Abril de 2020, v. 7, n. 1.

DAS, Veena. Violence, Gender and Subjectivity. Annual Review of Anthropology, 37, 2008, pp.283-99.

ELIACHEFF, Caroline. LARIVIÈRE, Daniel. El tiempo de las víctimas. Madrid: Ediciones Akal, 2009.

FOUCAULT, Michel. Eu, Pierre Rivière, que degolei minha mãe, minha irmã e meu irmão. Rio de Janeiro: Edições Graal, 1977.

GARGALLO, Francesca. Ideas Feministas Latinoamericanas. México: UACM, 2014.

HARTSOCK, Nancy. "The Feminist Standpoint: Developing the Ground for a Specifically Feminism Historical Materialism". In: HARDING, Sandra, HINTIKKA, M.B, Discovering Reality, 1983. 


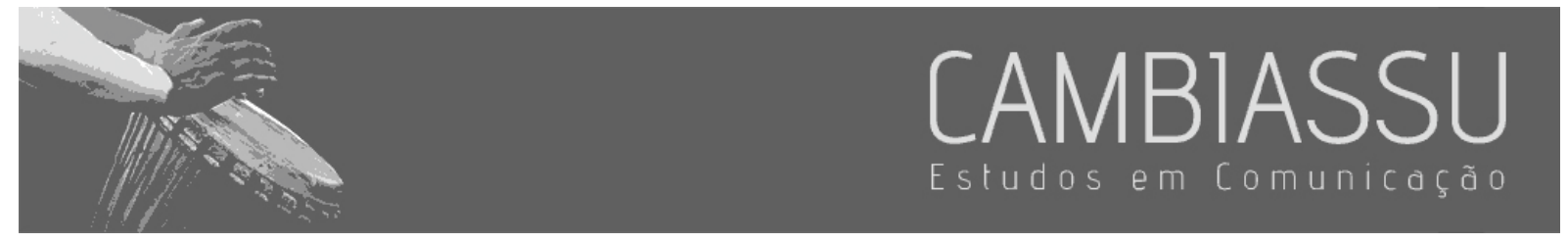

HIERRO, Graciela. Ética y Feminismo. Unam: Ciudad de Mexico, 1985.

JOSIOWICZ, Alejandra. Simpósio: Cinco questões sobre os Estudos de Gênero na América Latina. Estudos Históricos Rio de Janeiro, vol. 33, no 70, p. 227-253, Maio-Agosto 2020.

MCLAREN, Margaret A. Foucault, Feminismo e Subjetividade. São Paulo: Intermeios, 2016.

PIMENTEL, Silvia Carlos da Silva ; PANDJIARJIAN, Valéria . Legítima Defesa da Honra. llegítima impunidade de assassinos: um estudo crítico da legislação e jurisprudência da América Latina. In: Vida em família: uma perspectiva comparativa sobre "crimes de honra". Campinas: UNICAMP/PAGU, 2006.

SARTI, Cynthia. A vítima como figura contemporânea. Caderno CRH. Salvador, v. 24, n. 61, Jan-Abr 2011.

SEGATO, Rita. Contra-pedagogías de la crueldade. Buenos Aires: Prometeo Libros, 2018.

Las estructuras elementales de la violencia: ensayos sobre género entre la antropologia, el psicoanálisis y los derechos humanos. 2a ed. Buenos Aires: Prometeo Libros, 2010.

SODRÉ, Muniz. Por um conceito de Minoria. In: Raquel Paiva; Alexandre Barbalho. (Org.). Comunicação e Cultura das Minorias. 1ed.São Paulo: Paulus, 2005.

VIANNA, Adriana; LOWENKRON, Laura. O duplo fazer do gênero e do Estado: interconexões, materialidades e linguagens. In: Cadernos Pagu: Dossiê Gênero e Estado: formas de gestão, práticas e representações. Rio de Janeiro, 2017.

WIEVIORKA, Michel. O novo paradigma da violência. Tempo Social; Rev. Sociologia USP, São Paulo, maio/1997. 